\title{
Implications of China's Aerospace Industrial Policies
}

Chad J. R. Ohlandt 
For more information on this publication, visit www.rand.org/pubs/testimonies/CT456.html

\section{Testimonies}

RAND testimonies record testimony presented or submitted by RAND associates to federal, state, or local legislative committees; government-appointed commissions and panels; and private review and oversight bodies.

Published by the RAND Corporation, Santa Monica, Calif.

C Copyright 2016 RAND Corporation

RAND $\mathbb{R}$ is a registered trademark.

\section{Limited Print and Electronic Distribution Rights}

This document and trademark(s) contained herein are protected by law. This representation of RAND intellectual property is provided for noncommercial use only. Unauthorized posting of this publication online is prohibited. Permission is given to duplicate this document for personal use only, as long as it is unaltered and complete. Permission is required from RAND to reproduce, or reuse in another form, any of its research documents for commercial use. For information on reprint and linking permissions, please visit www.rand.org/pubs/permissions.html. 


\section{Implications of China's Aerospace Industrial Policies}

Testimony of Chad J. R. Ohlandt ${ }^{1}$

The RAND Corporation ${ }^{2}$

Before the U.S.-China Economic and Security Review Commission

April 27, 2016

$\mathrm{T}$ hank you, Chairman Shea and Vice-Chairman Bartholomew, for the opportunity to testify today on China's aerospace industrial polices. The government policy of the People's Republic of China (PRC) directly strives to create aerospace national champions that not only support their domestic market but are also globally competitive. Given that, in 2015 , the United States exported more than $\$ 125$ billion of aerospace products, resulting in a trade surplus of $\$ 66$ billion from the U.S. aerospace manufacturing sector, ${ }^{3}$ the creation of a strong Chinese global competitor has the potential to affect the U.S. economy and employment. Aerospace technology plays a critical role in defense and national security, and the success of PRC government policy would have national security implications as well.

The PRC's recent 13th Five-Year Plan (2016-2020) on National Economic and Social Development identifies aerospace as a core technology for whole-of-government support and development, as well as a sector for promoting international cooperation in manufacturing. It specifically refers to a new generation of aviation equipment and world-class aviation hubs. None of this is new; aerospace has long been identified as such in the PRC's high-level five-year plans. Existing lower-level PRC government policies are more specific about developing globally competitive commercial aviation and space industries. Nonetheless, while the PRC has steadily improved its aerospace technology base, the effort has not yet resulted in any globally competitive products or major companies and has had limited impact on the U.S. aerospace sector.

\footnotetext{
${ }^{1}$ The opinions and conclusions expressed in this testimony are the author's alone and should not be interpreted as representing those of the RAND Corporation or any of the sponsors of its research.

${ }^{2}$ The RAND Corporation is a research organization that develops solutions to public policy challenges to help make communities throughout the world safer and more secure, healthier and more prosperous. RAND is nonprofit, nonpartisan, and committed to the public interest.

3 Aerospace Industries Association, "U.S. Aerospace Trade Balance," 2015. As of April 20, 2016: http://www.aia-aerospace.org/assets/Series_08_-_Balance.pdf
} 
The rest of this testimony provides market context to understand the impact of the PRC's aviation policies, background on those policies, and suggestions for U.S. policy options. These comments are based on two RAND publications, Ready for Takeoff: China's Advancing Aerospace Industry and The Effectiveness of China's Industrial Policies in Commercial Aviation Manufacturing, available on the RAND website. ${ }^{4}$

\section{Commercial and General Aviation Manufacturing}

Aerospace broadly includes both aviation and space industries. Those two categories can be further divided into manufacturing and services (e.g. airlines, satellite communications.) PRC aerospace industrial policy is more likely to affect U.S. commercial and general aviation manufacturing than other components of the aerospace sector. Although there is a vibrant global private space sector, the satellite and space launch industry remains dominated by government defense and civilian scientific funding. Regardless of the success of PRC industrial policy, it is unlikely that the PRC will capture significant space-related revenues from foreign governments. The airline transportation industry requires government permission to fly in sovereign airspace, and the government allocates landing slots. This generally results in reciprocal treatment between countries; approved international routes between China and another nation will have roughly the same passenger capacity available to airlines based in each, and industrial policy impact will be greater on the domestic market. Given the very significant roles of government in those aerospace sectors, PRC industrial policy alone is unlikely to have a major impact on space industries or airlines. In contrast, the manufacturing of aviation vehicles is a highly competitive global market that could be affected by PRC industrial policy.

Commercial aviation refers to all scheduled passenger airlines, while general aviation is everything else. From an economic perspective, commercial aviation is far more significant. Commercial aviation manufacturing is further divided into two segments, large commercial aircraft (LCA) and regional jets. LCA includes narrow-body and wide-body aircraft, or singleaisle and multi-aisle aircraft, respectively. Two commercial companies, Boeing and Airbus, currently dominate LCA manufacturing. Similarly, the regional jet market is primarily split between two competitors, Bombardier and Embraer. Other regional jet manufacturers exist, but they have historically produced less than 10 percent of the aircraft that the two leading manufacturers have. Boeing and Airbus currently each produce more than 600 aircraft per year, while Bombardier and Embraer each produce 50-100 aircraft annually.

The large investment required to design an LCA and the years necessary to develop global supply chains and sustainment partners are significant barriers to entry. Airlines also prefer the cost-efficiency of operating the minimum number of aircraft models (e.g., the Southwest Airlines model of operating only Boeing 737s.) Lastly, the LCA production rate is relatively low in

\footnotetext{
${ }^{4}$ Roger Cliff, Chad J. R. Ohlandt, and David Yang, Ready for Takeoff: China's Advancing Aerospace Industry, Santa Monica, Calif.: RAND Corporation, MG-1100-UCESRC, 2011 (www.rand.org/t/mg1100); and Keith Crane, Jill E. Luoto, Scott Warren Harold, David Yang, Samuel K. Berkowitz, and Xiao Wang, The Effectiveness of China's Industrial Policies in Commercial Aviation Manufacturing, Santa Monica, Calif.: RAND Corporation, RR245, 2014 (www.rand.org/t/rr245).
} 
comparison to, say, automotive or semiconductor manufacturing, suggesting that even moderately greater production rates lead to significant efficiency advantages. All of these factors in combination drive the aircraft manufacturing market toward a duopoly structure. Although there are other regional jet producers and a half-dozen business jet manufacturers worldwide, they are unable to capture enough market share to achieve significant scales of efficiency to be competitive with the market leaders; thus, they remain niche providers of aircraft to those who do not operate large aircraft fleets. Those efficiencies include manufacturing advantages and technology development. Boeing and Airbus maintain manufacturing and technological leads over the regional jet leaders, who in turn have similar advantages over business jet manufacturers. In both cases, those advantages create barriers to entry for potential competitors. Realistically, significant disruption in the existing commercial aircraft business is likely only if those leaders fail to maintain their advantages and create an opportunity for competitors.

The nature of aviation manufacturing supply chains is more varied and complex. Subsystems and components of commercial aircraft can sometimes be produced by a large variety of industrial companies, such as with interior fittings, or by only one or two companies, such as with jet engines, depending on the complexity involved.

\section{China and Commercial Aviation}

Boeing and Airbus both annually produce 20 -year market outlooks for commercial aircraft. While the outlooks are understandably optimistic, they are reasonable projections of the market based on straight-line projections of current trends. In 2015, Boeing projects an average total demand of 1,900 commercial aircraft of all sizes annually over the next 20 years, roughly 23 percent more than the combined current production rate of 1,542 in $2015 .^{5}$ Of that total demand, 38 percent is projected to come from Asia, including 17 percent from China alone. Boeing projects that China would purchase more than 300 commercial aircraft annually over the next 20 years on average, which would triple the size of the fleet in China. Airbus projections are slightly less optimistic but similar.

China has a significant aviation manufacturing industry that produces military aircraft for the People's Liberation Army (PLA), but it has limited experience with commercial aircraft. In order to advance the Chinese aviation manufacturing industry according to five-year plans, the PRC historically has promoted joint ventures with Western companies and encouraged domestic assembly of aircraft. Both Airbus and Embraer perform final assembly of some jets in China today. While China's aviation manufacturing industry has advanced and matured, these joint ventures have had limited success. One possible reason is that the Chinese economic advantage of cheap labor has limited utility, because aviation manufacturing requires highly skilled labor.

In 2008, the PRC established a "national champion," the Commercial Aircraft Corporation of China (COMAC), for the purpose of designing and producing commercial aircraft. COMAC is in the process of developing and launching a regional jet, the ARJ21, and a single-aisle LCA, the

\footnotetext{
${ }^{5}$ Boeing, Current Market Outlook 2015-2034, 2015. As of April 20, 2015: http://www.boeing.com/resources/boeingdotcom/commercial/about-ourmarket/assets/downloads/Boeing_Current_Market_Outlook_2015.pdf
} 
C919. COMAC is funded by loans from state-owned banks, and state-owned airlines have been compelled to order these aircraft. Foreign suppliers to the C919 must enter into joint ventures in order to participate.

However, both aircraft programs are years behind schedule. The first ARJ21 regional jet was just delivered in 2016, after more than 15 years of development. It lacks both U.S. Federal Aviation Administration (FAA) and European Aviation Safety Agency (EASA) certification, although approved by Chinese authorities in 2014. Recent comments on the C919 suggest first flight in 2017, with possible deliveries the following year ${ }^{6}$; it is hard to know how realistic those dates are. There are more than 300 orders for the ARJ21 and more than 500 for the C919, but those orders are not contractually binding, leaving firm demand unclear. The orders are primarily from PRC airlines and aircraft leasing companies.

One important uncertainty about the future success of these new systems is that neither aircraft, nor COMAC, has any established history of operating costs or safety records. At best, the ARJ21 and C919 are comparable with aircraft already in production and being widely operated today. The cost of operating an aircraft over its lifetime is significantly more than the purchase cost. So, even if the COMAC aircraft are cheaper to produce or are subsidized, the likely greater operating costs can be a serious disincentive to prospective customers. Before the C919 sees first flight, let alone production, both Boeing and Airbus are likely to be delivering aircraft that are more cost-efficient than those used today. Without additional safety certifications, the aircraft cannot fly outside the domestic Chinese market. While the ARJ21 is now in production, Boeing projects that only 3 percent of the 300 commercial aircraft that China demands annually are regional jets, barely ten per year.

While the PRC protectionist industrial policies are designed to support PRC domestic demand for the ARJ21 and the C919, domestic routes are flown by domestic airlines, mostly state-owned companies, which will have to bear the expected greater operating costs. Domestic airlines will seek to minimize operating costs across their fleets. If the ARJ21 and C919 are expensive to operate, they will be used only when there is no alternative aircraft. When the aircraft are used, Chinese airlines will be less competitive, primarily with alternative domestic transportation, such as traditional and high-speed rail, which already have an advantage in China because of the high population density. For LCA, even if the C919 meets expectations and PRC industrial policies allow it to corner the Chinese domestic market, it would, at best, amount to 17 percent of the anticipated global market for commercial aircraft, not enough to deny Boeing and Airbus their competitive advantages on the global market. Nonetheless, COMAC can continue on this path as long as the PRC continues to subsidize COMAC through either bank loans or industrial policies.

\section{Policy Options for the United States}

While there is no immediate expectation that China will achieve its goal of being a viable global competitor in the commercial aviation market, U.S. policymakers can take several steps to

\footnotetext{
${ }^{6}$ Siva Govindasamy, “China's Comac Aims for First C919 Flight by Early 2017," Reuters, February 23, 2016. As of April 20, 2015: http://www.reuters.com/article/us-coma-china-c-idUSKCN0VW110
} 
minimize the potentially distorting impacts of PRC industrial policies. Such steps include the following:

- Engage the European Union to establish a consensus on aerospace industrial policy norms. Although beyond the scope of this testimony, there are unresolved disagreements about government support to Boeing and Airbus. Without consensus, it is hard to hold China accountable to any standards.

- Work toward improving transparency of Chinese aerospace actors, by providing more clarity on aircraft purchases by Chinese state-owned airlines, implementing more intellectual property safeguards in the context of component certifications by the FAA or EASA, and increasing voluntary reporting by U.S. suppliers that have China-based operations on how investment decisions have been influenced by PRC industrial policy.

- Continue to monitor PRC aerospace industrial policy and work through bilateral and World Trade Organization forums to eliminate, in general, industry-specific policies and, in particular, to prevent these industrial policies from supporting the entry of the C919 or future COMAC aircraft into foreign markets.

Thank you for the opportunity to provide testimony today. I look forward to supporting the commission in its important work. 